\title{
Interactions Between, and Effectiveness of, Power System Stabilizers and FACTS Device Stabilizers in Multimachine Systems
}

\author{
Michael J. Gibbard, Member, IEEE, David J. Vowles, Member, IEEE, and Pouyan Pourbeik, Member, IEEE
}

\begin{abstract}
In this paper it is shown that interactions occur between stabilizers in multimachine power systems, the stabilizers being Power System Stabilizers (PSS's), FACTS device stabilizers (FDS's) or both. The interactions, which are identified and quantified, may enhance or degrade the damping of certain modes of rotor oscillation. In particular, interactions between PSS's are found to adversely affect the damping of inter-area modes. The analysis of interactions also provides a practical means for quantifying and assessing simultaneously the relative effectiveness of both PSS's and FDS's in damping the rotor modes of oscillation. This is achieved using a stabilizer damping contribution diagram. A theoretical basis is given for the analysis of interactions and the effectiveness of stabilizers; the practical significance and applications are illustrated using a case study on a 3-area, 400 state system having 28 generator groups and a number of FDS's. For systems of more than 600-700 states the modified Arnoldi method is used for eigenanalysis-based calculations.
\end{abstract}

Index Terms—stabilizers, damping, interactions.

\section{INTRODUCTION}

$\mathbf{S}$ YNCHRONIZING and damping torque concepts form the basis for the design of both Power System Stabilizers (PSS's) [1], [2], [5] and FACTS device stabilizers (FDS's) [6]. The advantage of this approach is that it provides both engineering insight and understanding of the action of the stabilizers in enhancing the damping performance of multimachine power systems. However observations from both field tests and analysis reveal that the damping of inter-area modes tends to be inferior to that expected from the design of multimachine PSS's based on damping torque concepts. As noted in [4], "The characteristics of these modes ... and the factors influencing them, are not fully understood". Similarly, the damping of local-area modes is observed to differ from expected levels. It will be shown in the analysis and case studies that degradation or enhancement in damping of the rotor modes can be attributed to interactions between stabilizers as well as the inertia-weighted speed-participation of a given generator in the particular mode.

The transfer functions (TF's) of both PSS's and FDS's are of the form $\left[k_{j}, G_{j}(s)\right]$, a structure which is commonly employed

Manuscript received November 20, 1998; revised May 27, 1999.

M. J. Gibbar and D. J. Vowles are with the Department of Electrical and Electronic Engineering, The University of Adelaide, Adelaide, South Australia 5005.

P. Pourbeik is with Power Systems Energy Consulting, GE Power Systems, Schenectady, NY 12345, USA.

Publisher Item Identifier S 0885-8950(00)03814-1. in the industry. The TF $G_{j}(s)$ is designed to effect a left-shift of the selected rotor modes, the extent of the left-shift is determined primarily by the setting of the gain $k_{j}$ (which, in the case of PSS's, is also the value of the damping torque coefficient introduced through the action of PSS $j$ [1]). The design of the robust, fixed-parameter stabilizers is outlined briefly in the Appendix; the design procedures are employed by Australian utilities [5]. It should be noted, however, that the techniques which will be described to analyze interactions and assess the relative effectiveness of stabilizers can be applied to multimachine PSS's and FDS's designed by other methods as long as increases in gains of the stabilizers result in a predominantly left shift of the rotor modes.

The layout of the paper is as follows. The analysis of interactions is based on the analysis of both the perturbations in induced torque coefficients (ITC's) and the shifts in rotor modes resulting from increments in stabilizer gains, $\Delta k_{j}$. Consequently, the concept of a torque induced on the generator rotor by any PSS or FDS is introduced; this is followed by the derivation of expressions both for the ITC's and for the mode shifts in terms of the gain, $\Delta k_{j}$. The concept of interactions between stabilizers is then explained and a case study on a reduced, eleven-machine system with two SVC's is used to reveal the significant features of interactions. The mode shifts, which are net of interactions and which result from increments in the gains of each PSS or FDS, are most usefully displayed in the form of a stabilizer damping contribution diagram. In a second case study, which includes both PSS's and a variety of FACTS devices, this diagram is shown to reveal simultaneously the relative effectiveness of all stabilizers for selected modes of rotor oscillation. Such information can also form the basis for simultaneously coordinating both PSS's and FDS's.

\section{CONCEPT OF AN INDUCED TORQUE}

In Fig. 1 is shown a linearized model of a multimachine power system in which generator $j$ is fitted with a PSS. For generator $j$, consider the signal path from speed perturbation $\Delta \omega_{j}$ through PSS $j$ to the component of electrical torque, $\Delta P e_{j}$, on machine $j$. Consequently, at a mode of rotor oscillation, $\lambda_{h}, \Delta P e_{j}$ includes a torque component $\Delta P_{j j}$ induced on the shaft of generator $j$ by its own PSS [1]. However, there is also signal path from $\Delta \omega_{j}$ through PSS $j$ and the power system to the electrical torque component $\Delta P_{i j}$ on generator $i$. That component of $\Delta P_{i j}$ in phase with the speed perturbation $\Delta \omega_{i}$ on generator 

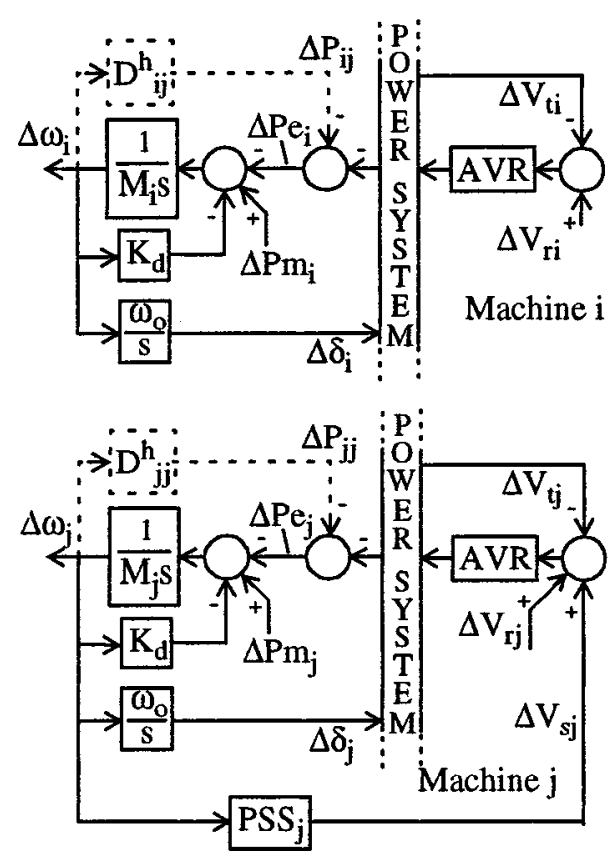

Fig. 1. Torque components $\Delta P_{j j}$ and $\Delta P_{i j}$ induced on machines $j$ and $i$ by PSS $j$.

$i$ is a damping torque induced on generator $i$ through the action of PSS $j$. The interaction of PSS $j$ with generator $i$ was first noted in [2].

A similar concept of induced torques can be illustrated for FDS's [6]. There is a signal path from the local FDS stabilizing signal through FDS $j$ and the network to the electric torque component, $\Delta P_{i j}$ on generator $i$. Again the component of $\Delta P_{i j}$ in phase with speed $\Delta \omega_{i}$ on generator $i$ is a damping torque induced on the generator by the action of FDS $j$. For the purpose of analysis, however, it is more convenient to define an induced torque coefficient rather than consider induced torques.

\section{A. Induced Torque Coefficients}

A perturbation in the input signal on stabilizer $j$ induces on the shaft of generator $i$ a component of electrical torque, $\Delta P_{i j}$. It was shown in [6] that this induced torque is related to the speed perturbation of generator, $i, \Delta \omega_{i}$, by a complex induced torque coefficient (ITC), $D_{i j}^{h}$, defined by

$$
\Delta P_{i j}\left(\lambda_{h}\right)=D_{i j}^{h} \Delta \omega_{i}\left(\lambda_{h}\right)
$$

This relation can be represented as illustrated in Fig. 1 by the section in dotted lines. By using parameter perturbation analysis on a $n$ machine system, an expression can be derived for the incremental induced torque coefficient on generator $i$ due to an increment in the gain $\left(\Delta k_{j}\right)$ on $\operatorname{FDS} j$ :

$$
\Delta D_{i j}^{h}=H_{P U r_{-} i j}\left(\lambda_{h}\right)\left(c_{q *} u_{* h} / u_{i h}\right)\left[G_{j}\left(\lambda_{h}\right) \Delta k_{j}\right]
$$

where $H_{P U r_{-} i j}(s)$ is the TF from the reference input voltage $\Delta U r_{j}$ of the FDS controller $j$ to the electric torque component on generator $i$ and is calculated with the shaft dynamics of all machines disabled [6]; $\boldsymbol{c}_{q_{*}}$ is the state output vector for the stabilizing signal used as the FDS input; $\boldsymbol{u}_{* h}$ is the right eigenvector of mode $\lambda_{h}$, and $u_{i h}$ is the element corresponding to the speed state of machine $i$. Likewise, for speed-input PSS's,

$$
\Delta D_{i j}^{h}=H_{P V r_{-} i j}\left(\lambda_{h}\right)\left(u_{j h} u_{i h}\right)\left[G_{j}\left(\lambda_{h}\right) \Delta k_{j}\right]
$$

where $H_{P V r_{-} i j}(s)$ is the PVr TF from the AVR reference input on generator $j$ to the electric power output on generator $i$, also calculated with the shaft dynamics of all machines disabled [2], [3], [8]. For PSS's, a case of special interest is the incremental ITC on generator $i\left(\Delta D_{i i}^{h}\right)$ produced by an increment in the gain $\left(\Delta k_{i}\right)$ on its own PSS $i$, [in which case $u_{j h}=u_{i h}$ in (3)]. This ITC is referred to as the self-induced torque coefficient. Because the PSS design procedure requires that $G_{i}(j \omega) \approx$ $1 / H_{P V r_{-} i i(j \omega)}$ over the range of frequencies of rotor modes, (3) becomes

$$
\Delta D_{i i}^{h} \approx \Delta k_{i}
$$

There is thus an equivalence between the pu PSS gain and the damping torque coefficient. This result not only is consistent with the approach to the design of PSS's outlined in section Appendix A but also provides a useful measure of the effects of PSS gain changes. We will show that the self-induced damping torque coefficient on machine $i$, i.e., $\Delta k_{i}$, is thus enhanced or degraded by effects induced by other PSS's and by FDS's.

\section{Estimating the Mode ShIFT Due to AN InCREMENT IN STABILIZER GAIN}

Based on [6] it can be shown that, as a first-order approximation, the shift in the $h$ th mode of rotor oscillation is related to an incremental change in the torque coefficient, $\Delta D_{i j}^{h}$, on machine $i$ by:

$$
\Delta \lambda_{i j}^{h}=-\left(p_{i h} / M_{i}\right) \Delta D_{i j}^{h}
$$

where $p_{i h}$ is the complex speed participation of generator $i$ in mode $h ; M_{i}$ is twice the generator's inertia constant. By substitution of (2) or (3) in (5), a general expression for the contribution to the mode shift by generator $i$ due to an increment in gain on stabiliser $j$ is

$$
\Delta \lambda_{i j}^{h}=-\left(p_{i h} / M_{i}\right) H_{p * r_{-} i j}\left(\lambda_{h}\right)\left(\boldsymbol{c}_{q *} \boldsymbol{u}_{* h} / u_{i h}\right)\left[G_{j}\left(\lambda_{h}\right) \Delta k_{j}\right]
$$

where stabilizer $j$ may be a PSS or a FDS. Let

$$
\phi_{i j}\left(\lambda_{h}\right)=H_{p * r_{-i j}}\left(\lambda_{h}\right)\left(\boldsymbol{c}_{q *} \boldsymbol{u}_{* h} / u_{i h}\right)
$$

then (6) becomes

$$
\Delta \lambda_{i j}^{h}=-\left(p_{i h} / M_{i}\right) \varphi_{i j}\left(\lambda_{h}\right)\left[G_{j}\left(\lambda_{h}\right) \Delta k_{j}\right] .
$$

Three additional expressions will be employed in later sections. The first is the contribution to the mode shift by all $n$ generators as a result of an increment in gain on any stabiliser $j$ only, i.e.

$$
\left.\Delta \lambda^{h}\right|_{\text {stab }-j}=-\left(\sum_{i=1}^{n}\left(p_{i h} / M_{i}\right) \varphi_{i j}\left(\lambda_{h}\right)\right)\left[G_{j}\left(\lambda_{h}\right) \Delta k_{j}\right] .
$$


The second expression is the contribution by generator $i$ to the mode shift caused by increments in the gains in all $n$ PSS's and $z$ FDSs:

$$
\left.\Delta \lambda^{h}\right|_{\text {geb_ } \__{i}}=-\left(p_{i h} / i\right) \cdot \sum_{j=1}^{n+z} \varphi_{i j}\left(\lambda_{h}\right)\left[G_{j}\left(\lambda_{h}\right) \Delta k_{j}\right] .
$$

Thirdly, the total contribution to the mode shift by all $n$ generators as a result of increments in the gain on all $n+z$ stabilizers:

$$
\Delta \lambda^{h}=-\sum_{j=1}^{n+z} \sum_{i=1}^{n}\left(p_{i h} / M_{i}\right) \varphi_{i j}\left(\lambda_{h}\right)\left[G_{j}\left(\lambda_{h}\right) \Delta k_{j}\right] .
$$

Again, a case of special interest is the contribution by generator $i$ to the mode shift due to an increment in its PSS gain, $\Delta k_{i}$. By substitution of (4) in (5), this self-contribution is found to be:

$$
\Delta \lambda_{i i}^{h} \approx-\left(p_{i h} / M_{i}\right) \Delta k_{i i}
$$

This result provides a type of benchmark for the contribution of a PSS to damping. Typically if a machine participates significantly in a mode (usually a local-area mode), the speed participation is about 0.5 . The mode shift is then directly to the left in the s-plane and is equal to $\Delta k_{i} /\left(2 M_{i}\right)$. Clearly with low participation in the speed state the extent of the mode shift is reduced. However, a reduced contribution to the mode shift may also be attributed in part to the effect of interactions. The concept of interactions is discussed next.

\section{INTERACTIONS BETWEEN STABILIZERS}

To illustrate the concept of interactions in its simplest form, let us assume that increments $\Delta k_{i}$ and $\Delta k_{j}$ are made in the gain of the PSS on generator $i$ and in the gain of another stabiliser $j$ (a PSS or a FDS). Based on (10) and (12) above, the contribution to the mode shift by generator $i$ is

$$
\left.\Delta \lambda^{h}\right|_{\text {gen } \_i}=-\left(p_{i h} / M_{i}\right)\left[\Delta k_{i}+\alpha_{i j}\left(\lambda_{h}\right) \Delta k_{j}\right]
$$

where $\alpha_{i j}\left(\lambda_{h}\right)$ is a complex number. If both stabilizer gains are increased, it is apparent from (13) that the gain increment $\Delta k_{j}$ can be considered to modify the effect of the gain increment on the left-shift of the mode; the effect, however, depends on the sign of the real part of $\alpha_{i j}\left(\lambda_{h}\right)$. For example, if the sign is negative, incrementing the gain on PSS $i$ only is more effective than incrementing the gains on PSS $i$ and stabilizer $j$. Consequently, from the point of view of adjustment to the gain settings, there appears to be a negative interaction between stabilizer $j$ and PSS $i$. On the other hand, if the sign of $\mathfrak{R}\left(\alpha_{i j}\left(\lambda_{h}\right)\right)$ is positive, the enhanced contribution to damping is associated with a positive interaction between stabilizer $j$ and PSS $i$. Let us call the such interactions stabilizer interactions; another form of interaction is shown below.

From a practical point of view, it is more informative to consider the contribution to the mode shift by the $n$ generators resulting from a gain increment on stabilizer $j$ only. If the latter is a PSS this contribution can be expressed from (5) as

$$
\left.\left.\Delta \lambda^{h}\right|_{\text {stab }_{-j}}=-\left(p_{j h} / M_{j}\right) \Delta D_{j j}^{h}+\sum_{i=1 \neq j}^{n}\left[-p_{i h} / M_{i}\right) \Delta D_{i j}^{h}\right](14)
$$

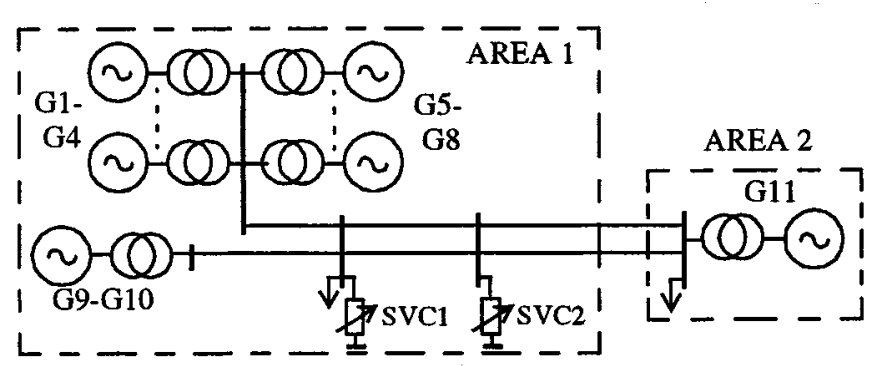

Fig. 2. Two-area power system.

or, alternatively, using (8) and (12), this contribution is

$$
\begin{gathered}
\left.\Delta \lambda^{h}\right|_{\text {stab }_{-j}} \approx-\left(\frac{p_{j h}}{M_{j}}\right) \Delta k_{j}+\sum_{i=1 \neq j}^{n}\left(\frac{-p_{i h}}{M_{i}}\right) \varphi_{i j}\left(\lambda_{h}\right) \\
\left.\cdot\left[G_{j} \lambda_{h}\right) \Delta k_{j}\right]
\end{gathered}
$$

The above equation reveals that the contribution to damping of generator $j$ due to its own PSS [the first term in (15)] may be enhanced or degraded due to contributions from, or interactions with, the remaining generators. Let us call such interactions generator interactions. The net effect of interactions is given by the second term and is proportional to $\Delta k_{j}$.

The second term in (14) for the mode shift, which results from an increment in gain on stabilizer $j$ only, consists of the incremental $\Delta D_{i j}^{h}$ weighted by the factor $\left(p_{i h} / M_{i}\right)$. The ITC $\Delta D_{i j}^{h}$ therefore in part determines the nature and extent of the interaction between stabilizer $j$ and machine $i$. In Case Study A it is demonstrated with numerical quantities that some further insight into the action of the $n+z$ stabilizers and the significance of their interactions is derived from an array of ITC's, i.e. $\Delta D_{i j}^{h}: i, j=1, \cdots, n+z$. Such insight is particularly informative when the arrays for local- and inter-area modes are examined. Additional insight is furnished when the associated arrays, $\Delta \lambda_{i j}^{h}: i, j=1, \cdots, n$, for the shifts in the same modes are studied.

\section{A. Case Study A: Nature and Significance of Interactions}

A simplified single-line diagram of the power system used in the case study is shown in Fig. 2. All generators are represented by higher-order models; generator 11 represents the system of Area 2. Generating units 1 to 4 are identical, so are 5 and 6,7 and 8, 9 and 10. The two SVC's are fitted with FDS's. While not a faithful representation, Fig. 2 depicts the South Australian network and the interconnection with the Eastern States.

For the selected operating condition there is zero power transfer between the two Areas and the outputs of all generators are at about $75 \%$ of rated. PSS's and FDS's, designed as in Section VII, are installed on generators and the SVCs; perturbations in rotor speed and real power flows in associated lines are used as the respective stabilizing signals.

\section{B. Nature of Stabilizer Interactions Revealed by an Array of Induced Torque Coefficients, $\Delta D_{i j}^{h}$}

For mode $h$, the incremental ITC on generator $i$ is related to an increment in gain on stabilizer $j$ by (2) or (3). In the study all PSS gains are set to $5 \mathrm{pu}$ on machine base and FDS gains 
TABLE I

ARRAYS OF INCREMENTAL ITCS, $\Delta D_{i}^{h}$, FOR INCREMENTS IN PSS \& FDS GAINS FOR LOCAL- AND INTER-AREA MODES; ARRAYS CALCULATED FROM EQUATIONS (2) OR (3). (Similar Results APPly to IdENTiCAl Machines IN THE SAME STATION)

\begin{tabular}{|c|c|c|c|c|c|c|c|c|c|c|c|c|c|c|}
\hline & \multicolumn{7}{|c|}{ Local-area mode $-0.824 \pm j 8.21$} & \multicolumn{7}{|c|}{ Inter-area mode $-0.294 \pm \mathrm{j} 3.74$} \\
\hline $\begin{array}{l}\text { Stab/ } \\
/ \text { Gen }\end{array}$ & $\begin{array}{c}\text { PSS1 } \\
\text { (\& 2-4) }\end{array}$ & $\begin{array}{l}\text { PSS5 } \\
\text { (\& 6) }\end{array}$ & $\begin{array}{l}\text { PSS7 } \\
(\& 8)\end{array}$ & $\begin{array}{c}\text { PSS9 } \\
(\& 10)\end{array}$ & PSS11 & $\begin{array}{c}\text { FDS } \\
\text { SVC1 }\end{array}$ & $\begin{array}{c}\text { FDS } \\
\text { SVC2 }\end{array}$ & $\begin{array}{c}\text { PSS1 } \\
(\& 2-4)\end{array}$ & $\begin{array}{l}\text { PSS5 } \\
\text { (\&6) }\end{array}$ & $\begin{array}{l}\text { PS\$7 } \\
\text { (\& 8) }\end{array}$ & $\begin{array}{l}\text { PSS9 } \\
\text { (\& 10) }\end{array}$ & PSS11 & $\begin{array}{c}\text { FDS } \\
\text { SVC1 }\end{array}$ & $\begin{array}{l}\text { FDS } \\
\text { SVC2 }\end{array}$ \\
\hline G1 & $\begin{array}{c}1.00 \\
-\mathrm{j} 0.15\end{array}$ & $\begin{array}{l}-0.03 \\
-j 0.01\end{array}$ & $\begin{array}{r}-0.04 \\
-\mathrm{j} 0.02\end{array}$ & $\begin{array}{c}0.12 \\
-\mathrm{j} 0.03\end{array}$ & $\begin{array}{c}0 \\
+\mathrm{j} 0\end{array}$ & $\begin{array}{c}0.01 \\
-\mathrm{j} 0.01\end{array}$ & $\begin{array}{c}0 \\
+\mathrm{j} 0 \\
\end{array}$ & $\begin{array}{l}1.01 \\
+\mathrm{j} 0\end{array}$ & $\begin{array}{l}-0.07 \\
-j 0.01\end{array}$ & $\begin{array}{r}-0.08 \\
+j 0.01 \\
\end{array}$ & $\begin{array}{c}-0.05 \\
+\mathbf{j} 0 \\
\end{array}$ & $\begin{array}{c}0 \\
-j 0 \\
\end{array}$ & $\begin{array}{c}0.31 \\
-j 0.25 \\
\end{array}$ & $\begin{array}{r}0.10 \\
-\mathrm{j} 0.04 \\
\end{array}$ \\
\hline G2 & $\begin{array}{r}-0.04 \\
+\mathrm{j} 0.02\end{array}$ & $\begin{array}{l}-0.03 \\
-j 0.01\end{array}$ & $\begin{array}{r}-0.04 \\
-\mathrm{j} 0.02\end{array}$ & $\begin{array}{c}0.12 \\
-\mathrm{j} 0.03\end{array}$ & $\begin{array}{c}0 \\
+\mathrm{j} 0\end{array}$ & $\begin{array}{c}0.01 \\
-\mathrm{j} 0.01\end{array}$ & $\begin{array}{c}0 \\
+\mathrm{j} 0\end{array}$ & $\begin{array}{r}-0.04 \\
+\mathrm{j} 0.01 \\
\end{array}$ & $\begin{array}{l}-0.07 \\
-j 0.01 \\
\end{array}$ & $\begin{array}{r}-0.08 \\
+j 0.01 \\
\end{array}$ & $\begin{array}{c}-0.05 \\
+\mathrm{j} 0\end{array}$ & $\begin{array}{c}0 \\
-j 0\end{array}$ & $\begin{array}{c}0.31 \\
-\mathrm{j} 0.25 \\
\end{array}$ & $\begin{array}{c}0.10 \\
-\mathrm{j} 0.04 \\
\end{array}$ \\
\hline G3 & $\begin{array}{r}-0.04 \\
+\mathrm{j} 0.02\end{array}$ & $\begin{array}{l}-0.03 \\
-\mathrm{j} 0.01 \\
\end{array}$ & $\begin{array}{l}-0.04 \\
-\mathrm{j} 0.02\end{array}$ & $\begin{array}{c}0.12 \\
-\mathrm{j} 0.03 \\
\end{array}$ & $\begin{array}{r}0 \\
+\mathrm{j} 0 \\
\end{array}$ & $\begin{array}{c}0.10 \\
-\mathrm{j} 0.04 \\
\end{array}$ & $\begin{array}{c}0 \\
+\mathrm{j} 0 \\
\end{array}$ & $\begin{array}{r}-0.04 \\
+\mathrm{j} 0.01 \\
\end{array}$ & $\begin{array}{c}-0.07 \\
-\mathrm{j} 0.01 \\
\end{array}$ & $\begin{array}{r}-0.08 \\
+\mathrm{j} 0.01 \\
\end{array}$ & $\begin{array}{c}-0.05 \\
+\mathrm{j} 0 \\
\end{array}$ & $\begin{array}{c}0 \\
-j 0 \\
\end{array}$ & $\begin{array}{c}0.31 \\
-j 0.25 \\
\end{array}$ & $\begin{array}{c}0.10 \\
-\mathrm{j} 0.04 \\
\end{array}$ \\
\hline G4 & $\begin{array}{r}-0.04 \\
+\mathrm{j} 0.02 \\
\end{array}$ & $\begin{array}{l}-0.03 \\
-\mathrm{j} 0.01 \\
\end{array}$ & $\begin{array}{r}-0.04 \\
-\mathrm{j} 0.02 \\
\end{array}$ & $\begin{array}{c}0.12 \\
-\mathrm{j} 0.03 \\
\end{array}$ & $\begin{array}{c}0 \\
+j 0 \\
\end{array}$ & $\begin{array}{c}0.01 \\
-\mathrm{j} 0.01 \\
\end{array}$ & $\begin{array}{c}0 \\
+\mathrm{j} 0 \\
\end{array}$ & $\begin{array}{r}-0.04 \\
+j 0.01 \\
\end{array}$ & $\begin{array}{l}-0.07 \\
-\mathrm{j} 0.01 \\
\end{array}$ & $\begin{array}{r}-0.08 \\
+j 0.01 \\
\end{array}$ & $\begin{array}{l}-0.05 \\
+\mathrm{j} 0 \\
\end{array}$ & $\begin{array}{c}0 \\
-j 0 \\
\end{array}$ & $\begin{array}{c}0.31 \\
-\mathrm{j} 0.25 \\
\end{array}$ & $\begin{array}{c}0.10 \\
-\mathrm{j} 0.04 \\
\end{array}$ \\
\hline G5 & $\begin{array}{r}-0.06 \\
+\mathrm{j} 0.08\end{array}$ & $\begin{array}{c}0.99 \\
-\mathrm{j} 0.24\end{array}$ & $\begin{array}{r}-0.10 \\
+j 0.02\end{array}$ & $\begin{array}{c}0.19 \\
-\mathrm{j} 0.18\end{array}$ & $\begin{array}{c}0 \\
-\mathrm{j} 0\end{array}$ & $\begin{array}{c}0 \\
-\mathrm{j} 0.02\end{array}$ & $\begin{array}{c}0 \\
-\mathrm{j} 0 \\
\end{array}$ & $\begin{array}{c}-0.04 \\
+j 0\end{array}$ & $\begin{array}{l}1.02 \\
+\mathrm{j} 0\end{array}$ & $\begin{array}{r}-0.07 \\
+\mathrm{j} 0.01 \\
\end{array}$ & $\begin{array}{c}-0.04 \\
-j 0\end{array}$ & $\begin{array}{c}0 \\
-\mathrm{j} 0 \\
\end{array}$ & $\begin{array}{c}0.24 \\
-j 0.38\end{array}$ & $\begin{array}{c}0.09 \\
-j 0.07\end{array}$ \\
\hline G6 & $\begin{array}{r}-0.06 \\
+\mathrm{j} 0.08\end{array}$ & $\begin{array}{r}-0.07 \\
+j 0.02 \\
\end{array}$ & $\begin{array}{r}-0.10 \\
+\mathrm{j} 0.02 \\
\end{array}$ & $\begin{array}{c}0.19 \\
-\mathrm{j} 0.18\end{array}$ & $\begin{array}{c}0 \\
-\mathrm{j} 0 \\
\end{array}$ & $\begin{array}{c}0 \\
-\mathrm{j} 0.02 \\
\end{array}$ & $\begin{array}{c}0 \\
-\mathrm{j} 0 \\
\end{array}$ & $\begin{array}{c}-0.04 \\
+j 0\end{array}$ & $\begin{array}{r}-0.07 \\
-j 0.01 \\
\end{array}$ & $\begin{array}{r}-0.07 \\
+j 0.01 \\
\end{array}$ & $\begin{array}{c}-0.04 \\
-\mathrm{j} 0\end{array}$ & $\begin{array}{c}0 \\
-j 0 \\
-j\end{array}$ & \begin{tabular}{|c|}
0.24 \\
$-j 0.38$ \\
\end{tabular} & $\begin{array}{c}0.09 \\
-\mathrm{j} 0.07 \\
\end{array}$ \\
\hline G7 & $\begin{array}{r}-0 \\
+\mathrm{j} 0.06\end{array}$ & $\begin{array}{r}-0.03 \\
+\mathrm{j} 0.03 \\
\end{array}$ & $\begin{array}{c}0.99 \\
-\mathrm{j} 0.23\end{array}$ & $\begin{array}{l}-0.02 \\
-\mathrm{j} 0.16 \\
\end{array}$ & $\begin{array}{c}0 \\
-\mathrm{j} 0 \\
\end{array}$ & $\begin{array}{c}0.01 \\
-\mathrm{j} 0.03 \\
\end{array}$ & $\begin{array}{c}0.01 \\
-\mathrm{j} 0\end{array}$ & $\begin{array}{r}-0.06 \\
+\mathrm{j} 0.04 \\
\end{array}$ & $\begin{array}{r}-0.10 \\
+j 0.06 \\
\end{array}$ & $\begin{array}{c}1.00 \\
-\mathrm{j} 0.04\end{array}$ & $\begin{array}{r}-0.08 \\
+\mathrm{j} 0.04\end{array}$ & $\begin{array}{c}0 \\
-\mathrm{j} 0 \\
\end{array}$ & $\begin{array}{c}0.47 \\
+j 0.14\end{array}$ & $\begin{array}{c}0.09 \\
\mathrm{j} 0.04 \\
\end{array}$ \\
\hline G8 & $\begin{array}{c}-0 \\
+\mathrm{j} 0.06\end{array}$ & $\begin{array}{r}-0.03 \\
+j 0.03 \\
\end{array}$ & $\begin{array}{r}-0.05 \\
+j 0.04 \\
\end{array}$ & $\begin{array}{c}-0.02 \\
-\mathrm{j} 0.16\end{array}$ & $\begin{array}{c}0 \\
-j 0 \\
\end{array}$ & $\begin{array}{c}0.01 \\
-\mathrm{j} 0.03 \\
\end{array}$ & $\begin{array}{c}0.01 \\
-\mathrm{j} 0\end{array}$ & $\begin{array}{r}-0.06 \\
+\mathrm{j} 0.04 \\
\end{array}$ & $\begin{array}{r}-0.10 \\
+j 0.06 \\
\end{array}$ & $\begin{array}{r}-0.10 \\
+j 0.06 \\
\end{array}$ & $\begin{array}{c}-0.08 \\
+\mathrm{j} 0.04\end{array}$ & $\begin{array}{c}0 \\
-j 0 \\
\end{array}$ & $\begin{array}{r}0.46 \\
+\mathrm{j} 0.14 \\
\end{array}$ & $\begin{array}{c}0.09 \\
\text { j0.04 }\end{array}$ \\
\hline G9 & $\begin{array}{c}0 \\
-\mathrm{j} 0.01\end{array}$ & $\begin{array}{c}0.01 \\
-\mathrm{j} 0.01\end{array}$ & $\begin{array}{c}0.01 \\
-j 0\end{array}$ & $\begin{array}{c}1.02 \\
-\mathrm{j} 0.25\end{array}$ & $\begin{array}{c}-0 \\
+\mathrm{j} 0\end{array}$ & $\begin{array}{c}-0.01 \\
+\mathrm{j} 0.01\end{array}$ & $\begin{array}{c}-0 \\
+j 0\end{array}$ & $\begin{array}{c}-0.05 \\
+\mathrm{j} 0.01\end{array}$ & $\begin{array}{r}-0.08 \\
+j 0.01\end{array}$ & $\begin{array}{r}-0.08 \\
+j 0.02\end{array}$ & $\begin{array}{c}1.00 \\
-\mathrm{j} 0.02\end{array}$ & $\begin{array}{c}0 \\
-j 0\end{array}$ & $\begin{array}{c}0.19 \\
-j 0.01\end{array}$ & $\begin{array}{c}0.05 \\
-\mathrm{j} 0.04\end{array}$ \\
\hline G10 & $\begin{array}{c}0 \\
-\mathrm{j} 0.01\end{array}$ & $\begin{array}{c}0.01 \\
-j 0.01\end{array}$ & $\begin{array}{c}0.01 \\
-\mathrm{j} 0\end{array}$ & $\begin{array}{c}0 \\
+\mathrm{j} 0.06 \\
\end{array}$ & $\begin{array}{r}-0 \\
+\mathrm{j} 0\end{array}$ & $\begin{array}{r}-0.01 \\
+j 0.01 \\
\end{array}$ & $\begin{array}{c}-0 \\
+j 0\end{array}$ & $\begin{array}{r}-0.05 \\
+j 0.01 \\
\end{array}$ & $\begin{array}{r}-0.08 \\
+\mathrm{j} 0.01 \\
\end{array}$ & $\begin{array}{r}-0.08 \\
+\mathrm{j} 0.02 \\
\end{array}$ & $\begin{array}{c}-0.02 \\
+j 0.02\end{array}$ & $\begin{array}{c}0 \\
-j 0\end{array}$ & $\begin{array}{c}0.19 \\
-\mathrm{j} 0.01 \\
\end{array}$ & $\begin{array}{c}0.05 \\
-\mathrm{j} 0.04 \\
\end{array}$ \\
\hline G11 & $\begin{array}{c}-0.61 \\
-\mathrm{j} 1.48\end{array}$ & $\begin{array}{l}-0.31 \\
-j 1.16\end{array}$ & $\begin{array}{c}0.49 \\
-j 1.45\end{array}$ & $\begin{array}{c}1.13 \\
+\mathrm{j} 0.57\end{array}$ & $\begin{array}{c}1.06 \\
-\mathrm{j} 0.13\end{array}$ & $\begin{array}{r}-0.19 \\
+j 0.03\end{array}$ & $\begin{array}{r}-1.23 \\
+\mathrm{j} 0.63\end{array}$ & $\begin{array}{c}0 \\
-\mathrm{j} 0\end{array}$ & $\begin{array}{c}0.02 \\
-\mathrm{j} 0\end{array}$ & $\begin{array}{l}0.02 \\
-\mathrm{j} \theta\end{array}$ & $\begin{array}{l}0.01 \\
+\mathrm{j} 0 \\
\end{array}$ & $\begin{array}{c}1.01 \\
+\mathrm{j} 0.06\end{array}$ & $\begin{array}{c}0.04 \\
+j 0.03 \\
\end{array}$ & $\begin{array}{r}-0.07 \\
-\mathrm{j} 0.09 \\
\end{array}$ \\
\hline
\end{tabular}

to $0.0025 \mathrm{pu}$ on 100MVA; these are low gain values. PSS and EDS gain increments $\Delta k_{j}$ are set to $1 \mathrm{pu}$ and $0.0005 \mathrm{pu}$ on their respective bases. Table I shows the arrays of incremental ITC's for a local-area mode, $\lambda_{1}=-0.824 \pm j 8.21$, and for the inter-area mode, $\lambda_{2}=-0.294 \pm j 3.74$.

For PSS's, an important feature of the arrays for both local- and inter-area modes is that the diagonal terms, $\Delta D_{i i}^{h} \approx \Delta k_{i}=1 \angle 0^{\circ}$ pu (heavy outline in Table I). This confirms that the PSS design procedure of Section VII ensures that each PSS induces an almost pure damping torque coefficient on the machine on which it is installed for both local- and inter-area modes. The real parts of the off-diagonal terms, $\Delta D_{i j}^{h}$, are predominantly negative in the case of the inter-area mode for PSS's 1 to 11, whereas for the local-area mode there are a number of elements with positive signs (in columns PSS 9 and 10). Thus, with reference to (14), it is to be expected that interactions will tend to degrade the damping of the inter-area mode while enhancing the damping of the local-area mode. For FDS's, it is noteworthy that the FDS on SVC1 in particular induces significant positive damping torque coefficients on the machines for the inter-area mode, but negligible amounts for the local-area mode. The FDS's are thus likely to contribute significantly to the damping of the inter-area mode and have no affect on the local mode.

\section{Nature of Stabilizer Interactions Revealed by an Array of Mode Shifts, $\Delta \lambda_{i j}^{h}$}

The contribution by generator $i$ to the shift in mode $h$ is related to the increment in gain on stabilizer $j$ by (8). Based on (8), arrays of contributions to the mode shifts are calculated as shown in Table II for both the local- and inter-area modes when the gains on all PSS's and FDS's are again increased by 1 pu and $0.0005 \mathrm{pu}$ on their respective bases. Each diagonal element is the self-contribution by a generator to the mode shift due to the $1 \mathrm{pu}$ increase in its PSS gain. As given by (9), summing the elements in the column of stabilizer $j$ provides the contribution to the total mode shift by that stabilizer. Let us compare, for both the local- and inter-area modes, the real part of the diagonal dement with that of the column sum for a given PSS. For example, for a 1 pu gain increment on PSS 9, Table II reveals:

- interactions not only increase the left-shift of the local-area mode from -294 to -315 units ( 1 unit being $10^{-4}$ ), but also reduce significantly the left-shift of the inter-area mode from -78 to -41 units;

- the extent of the net left-shift for the local-area mode is significantly greater than that for the inter-area mode $(-315$ and -41 units, respectively).

Note that the above interactions, associated with a gain increment on PSS $j$ only, are due to contributions to the mode shift by generators other than $j$.

Consider the diagonal elements of Table II concerning PSSs:

- It was noted earlier that the diagonal elements $\Delta D_{i i}^{h}$ of the array of ITC's in Table I are all close, ideally, to $1 \angle 0^{\circ}$ pu for a 1 pu increment in each of the PSS gains. From (5), the values of the diagonal terms in Table II, $\Delta \lambda_{i i}^{h}=$ $-\left(p_{i h} / M_{i}\right) . \Delta D_{i i}^{h}$, are determined by the inertia-weighted speed-participation factor, $P_{i h} / M_{i}$. Because this factor, shown in Fig. 3, varies markedly within and between the local- and inter-area modes, so does $\Delta \lambda_{i i}^{h}$.

The relative effects of PSS's on local- and inter-area modes are:

- The left shift $\Delta \lambda_{i i}^{h}$, calculated from (8), is significant only for those generators which participate markedly in the mode due to larger values of $p_{i h}$ revealed in Fig. 3. For 
TABLE II

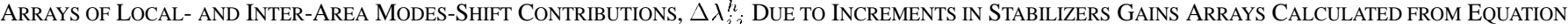
(8). Similar Results Apply for IDENTical Machines in tHe SAME Station (Shown IN BRACKeTs). (Multiply Values By $10^{-4}$ )

\begin{tabular}{|c|c|c|c|c|c|c|c|c|c|c|c|c|c|c|c|c|c|c|c|c|}
\hline & \multicolumn{10}{|c|}{ Local-area mode: $\lambda=-0.824 \pm j 8.213$} & \multicolumn{10}{|c|}{ Inter-area mode $\lambda=0.294 \pm \mathrm{j} 3.74$} \\
\hline $\begin{array}{c}\text { Stab } / \\
\ldots \ldots \\
/ \text { Gen }\end{array}$ & $\begin{array}{l}\text { PSS1 } \\
(2-4)\end{array}$ & $\begin{array}{c}\text { PSS5 } \\
(-6)\end{array}$ & $\begin{array}{r}\text { PSS7 } \\
(-8)\end{array}$ & & & $\begin{array}{l}\text { FDS1 } \\
\text { SVC1 }\end{array}$ & $\begin{array}{l}\text { FDS2 } \\
\text { SVC2 }\end{array}$ & $\begin{array}{l}\text { PSSs: } \\
\text { Row- } \\
\text { Sum }\end{array}$ & $\begin{array}{l}\text { FDSs: } \\
\text { Row- } \\
\text { Sum }\end{array}$ & Total & $\begin{array}{l}\text { PSS } \\
(2-4)\end{array}$ & $\begin{array}{c}\text { PSS5 } \\
(-6)\end{array}$ & $\begin{array}{r}\text { PSS7 } \\
(-8)\end{array}$ & $\begin{array}{l}\text { PSS9 } \\
(-10)\end{array}$ & $\begin{array}{c}\text { PSS } \\
11\end{array}$ & $\begin{array}{c}\text { FDS } \\
\text { SVC1 }\end{array}$ & $\begin{array}{c}\text { FDS } \\
\text { SVC2 }\end{array}$ & $\begin{array}{l}\text { PSSs: } \\
\text { Row- } \\
\text { Sum }\end{array}$ & $\begin{array}{l}\text { FDSs: } \\
\text { Row- } \\
\text { Sum }\end{array}$ & $\begin{array}{l}\text { Row- } \\
\text { Total }\end{array}$ \\
\hline G1 & $\begin{array}{r}-26 \\
+\mathrm{j} 22\end{array}$ & $\begin{array}{c}1 \\
-j 0\end{array}$ & $\begin{array}{c}2 \\
-\mathrm{j} 0\end{array}$ & & & $\begin{array}{c}0 \\
+\mathrm{j} 0\end{array}$ & $\begin{array}{c}0 \\
+\mathrm{j} 0\end{array}$ & $\begin{array}{r}-24 \\
+\mathrm{j} 23\end{array}$ & $\begin{array}{c}0 \\
+j 0\end{array}$ & & $\begin{array}{l}-44 \\
-\mathrm{j} 0\end{array}$ & $\begin{array}{c}3 \\
-j 0\end{array}$ & $\begin{array}{c}3 \\
-\mathrm{j} 1\end{array}$ & $\begin{array}{c}2 \\
-\mathrm{j} 0\end{array}$ & 0 & $\begin{array}{r}-13 \\
+\mathrm{j} 11\end{array}$ & $\begin{array}{c}-4 \\
+j 2 \\
\end{array}$ & $\begin{array}{l}-21 \\
-\mathrm{j} 3\end{array}$ & $\begin{array}{r}-17 \\
+j 13\end{array}$ & $\begin{array}{r}-38 \\
+\mathrm{j} 9\end{array}$ \\
\hline $\mathrm{G} 2$ & $\begin{array}{c}1 \\
-j 1 \\
\end{array}$ & $\begin{array}{c}1 \\
-j 0 \\
\end{array}$ & $\begin{array}{c}2 \\
-j 0 \\
\end{array}$ & $\begin{array}{r}-3 \\
+\mathrm{j} 3\end{array}$ & & $\begin{array}{c}0 \\
+\mathrm{j} 0 \\
\end{array}$ & $\begin{array}{r}0 \\
+j 0 \\
\end{array}$ & $\begin{array}{r}-24 \\
+j 23 \\
\end{array}$ & $\begin{array}{c}0 \\
+j 0 \\
\end{array}$ & $\begin{array}{r}-24 \\
+j 23 \\
\end{array}$ & $\begin{array}{c}2 \\
-\mathrm{j} 0 \\
\end{array}$ & $\begin{array}{c}3 \\
-j 0 \\
\end{array}$ & $\begin{array}{c}3 \\
-\mathrm{j} 1 \\
\end{array}$ & $\begin{array}{c}2 \\
-j 0 \\
\end{array}$ & $\begin{array}{r}0 \\
+\mathrm{j} 0 \\
\end{array}$ & $\begin{array}{r}-13 \\
+\mathrm{j} 11 \\
\end{array}$ & $\begin{array}{r}-4 \\
+j 2 \\
\end{array}$ & $\begin{array}{r}-21 \\
-j 3 \\
\end{array}$ & $\begin{array}{r}-17 \\
+j 13 \\
\end{array}$ & $\begin{array}{r}-38 \\
+\mathrm{j} 9 \\
\end{array}$ \\
\hline G3 & $\begin{array}{c}1 \\
-j 1\end{array}$ & $\begin{array}{c} \\
-j 0\end{array}$ & $\begin{array}{c}2 \\
-j 0\end{array}$ & $\begin{array}{c}-3 \\
+\mathrm{j} 3\end{array}$ & $+j$ & $\begin{array}{c}0 \\
+\mathrm{j} 0\end{array}$ & $\begin{array}{c}0 \\
+\mathrm{j} 0\end{array}$ & $\begin{array}{c}-24 \\
+\mathrm{j} 23\end{array}$ & $\begin{array}{c}0 \\
+\mathrm{j} 0\end{array}$ & $\begin{array}{c}-24 \\
+\mathrm{j} 23\end{array}$ & $\begin{array}{c}2 \\
-\mathrm{j} 0\end{array}$ & $\begin{array}{c}3 \\
-j 0\end{array}$ & $\begin{array}{c}3 \\
-\mathrm{j} 1\end{array}$ & $\begin{array}{c}2 \\
-\mathrm{j} 0\end{array}$ & $\begin{array}{c}0 \\
+\mathrm{j} 0\end{array}$ & $\begin{array}{c}-13 \\
+\mathrm{j} 11\end{array}$ & $\begin{array}{l}-4 \\
+\mathrm{j} 2\end{array}$ & $\begin{array}{l}-21 \\
-\mathrm{j} 3\end{array}$ & $\begin{array}{r}-17 \\
+\mathrm{j} 13\end{array}$ & $\begin{array}{r}-38 \\
+\mathrm{j} 9\end{array}$ \\
\hline G4 & $\begin{array}{c}1 \\
-j 1 \\
\end{array}$ & $\begin{array}{c}1 \\
-j 0\end{array}$ & $\begin{array}{c}2 \\
-\mathrm{j} 0 \\
\end{array}$ & $\begin{array}{r}-3 \\
+j 3 \\
\end{array}$ & 0 & $\begin{array}{c}0 \\
+\mathrm{j} 0 \\
\end{array}$ & $\begin{array}{c}0 \\
+\mathrm{j} 0 \\
\end{array}$ & $\begin{array}{r}-24 \\
+\mathrm{j} 23 \\
\end{array}$ & $\begin{array}{r}0 \\
+\mathrm{j} 0 \\
\end{array}$ & $\begin{array}{r}-24 \\
+\mathrm{j} 23 \\
\end{array}$ & $\begin{array}{c}2 \\
-\mathrm{j} 0 \\
\end{array}$ & $\begin{array}{c}3 \\
-\mathrm{j} 0\end{array}$ & $\begin{array}{c}3 \\
-j 1 \\
\end{array}$ & $\begin{array}{c}2 \\
-j 0 \\
\end{array}$ & $\begin{array}{r}0 \\
+\mathrm{j} 0 \\
\end{array}$ & $\begin{array}{r}-13 \\
+\mathrm{j} 11 \\
\end{array}$ & $\begin{array}{r}-4 \\
+\mathrm{j} 2 \\
\end{array}$ & $\begin{array}{l}-21 \\
-j 3 \\
\end{array}$ & $\begin{array}{r}-17 \\
+\mathrm{j} 13 \\
\end{array}$ & $\begin{array}{r}-38 \\
+\mathrm{j} 9 \\
\end{array}$ \\
\hline G5 & $\begin{array}{c}1 \\
+\mathrm{j} 0\end{array}$ & $\begin{array}{l}-8 \\
-j 8\end{array}$ & $\begin{array}{c}1 \\
+j 1\end{array}$ & $\begin{array}{l}-3 \\
-j 1\end{array}$ & & $\begin{array}{c}0 \\
+\mathrm{j} 0\end{array}$ & $\begin{array}{c}0 \\
-\mathrm{j} 0\end{array}$ & $\begin{array}{l}-7 \\
-j 7\end{array}$ & $\begin{array}{c}0 \\
+\mathrm{j} 0\end{array}$ & $\begin{array}{l}-7 \\
-j 7\end{array}$ & $\begin{array}{c}2 \\
-\mathrm{j} 0\end{array}$ & $\begin{array}{r}-68 \\
+j 2 \\
\end{array}$ & $\begin{array}{c}5 \\
-j 1\end{array}$ & $\begin{array}{c}2 \\
j 0\end{array}$ & $\begin{array}{c}0 \\
-j 0\end{array}$ & $\begin{array}{c}-17 \\
+j 25\end{array}$ & $\begin{array}{c}-6 \\
+j 5\end{array}$ & $\begin{array}{l}-40 \\
-j 0\end{array}$ & $\begin{array}{r}-23 \\
+j 30\end{array}$ & $\begin{array}{r}-63 \\
+j 30 \\
\end{array}$ \\
\hline G6 & $\begin{array}{c}1 \\
+\mathrm{j} 0\end{array}$ & $\begin{array}{c}1 \\
+\mathrm{j} 1\end{array}$ & $\begin{array}{c}1 \\
+\mathrm{j} 1\end{array}$ & $\begin{array}{l}-3 \\
-j 1\end{array}$ & $\begin{array}{r}0 \\
+\end{array}$ & $\begin{array}{c}0 \\
+\mathrm{j} 0\end{array}$ & $\begin{array}{c}0 \\
-\mathrm{j} 0\end{array}$ & $\begin{array}{l}-7 \\
-j 7\end{array}$ & $\begin{array}{c}0 \\
+\mathrm{j} 0\end{array}$ & $\begin{array}{l}-7 \\
-j 7\end{array}$ & $\begin{array}{c}2 \\
-j 0\end{array}$ & $\begin{array}{c}4 \\
-j 0\end{array}$ & $\begin{array}{c}5 \\
-j 1\end{array}$ & $\begin{array}{l}2 \\
\text { j0 }\end{array}$ & $\begin{array}{c}0 \\
-\mathrm{j} 0\end{array}$ & $\begin{array}{c}-17 \\
+\mathrm{j} 25\end{array}$ & $\begin{array}{c}-6 \\
+j 5\end{array}$ & $\begin{array}{l}-40 \\
-j 0\end{array}$ & $\begin{array}{r}-23 \\
+j 30\end{array}$ & $\begin{array}{c}-63 \\
+j 30\end{array}$ \\
\hline G7 & $\begin{array}{c}1 \\
-\mathrm{j} 0\end{array}$ & $\begin{array}{c}1 \\
+\mathrm{j} 0\end{array}$ & $\begin{array}{c}-11 \\
-j 14 \\
\end{array}$ & $\begin{array}{r}-3 \\
+\mathbf{j} 2\end{array}$ & $\begin{array}{l}0 \\
-j\end{array}$ & $\begin{array}{c}-1 \\
+\mathrm{j} 0\end{array}$ & $\begin{array}{c}0 \\
-\mathrm{j} 0\end{array}$ & $\begin{array}{r}-10 \\
-j 12\end{array}$ & $\begin{array}{c}0 \\
+\mathrm{j} 0\end{array}$ & $\begin{array}{l}-10 \\
-\mathrm{j} 12\end{array}$ & $\begin{array}{c}4 \\
-\mathrm{j} 2\end{array}$ & $\begin{array}{c}7 \\
-j 4\end{array}$ & $\begin{array}{r}-69 \\
+j 0\end{array}$ & $\begin{array}{c}6 \\
-j 3 \\
\end{array}$ & $\begin{array}{c}0 \\
-\mathrm{j} 0\end{array}$ & $\begin{array}{l}-32 \\
-\mathrm{j} 11 \\
\end{array}$ & $\begin{array}{l}-6 \\
-j 3 \\
\end{array}$ & $\begin{array}{c}-20 \\
-\mathrm{j} 25\end{array}$ & $\begin{array}{l}-38 \\
-j 13 \\
\end{array}$ & $\begin{array}{l}-58 \\
-j 39 \\
\end{array}$ \\
\hline G8 & $\begin{array}{c}1 \\
-\mathrm{j} 0\end{array}$ & $\begin{array}{c}1 \\
+\mathrm{j} 0\end{array}$ & $\begin{array}{c}1 \\
+j 0\end{array}$ & $\begin{array}{r}-3 \\
+\mathrm{j} 2 \\
\end{array}$ & $\overline{0}$ & $\begin{array}{c}-1 \\
+\mathrm{j} 0\end{array}$ & $\begin{array}{c}0 \\
-j 0\end{array}$ & $\begin{array}{c}-10 \\
-j 12\end{array}$ & $\begin{array}{c}0 \\
+j 0\end{array}$ & $\begin{array}{l}-10 \\
-j 12\end{array}$ & $\begin{array}{c}4 \\
-j 2\end{array}$ & $\begin{array}{c}7 \\
-j 4\end{array}$ & $\begin{array}{c}7 \\
-j 4\end{array}$ & $\begin{array}{c}6 \\
-\mathrm{j} 3\end{array}$ & $\begin{array}{c}0 \\
-j 0\end{array}$ & $\begin{array}{l}-32 \\
-\mathrm{j} 11\end{array}$ & $\begin{array}{l}-6 \\
-j 3\end{array}$ & $\begin{array}{l}-20 \\
-\mathrm{j} 25\end{array}$ & $\begin{array}{l}-38 \\
-\mathrm{j} 13\end{array}$ & $\begin{array}{l}.58 \\
. j 39\end{array}$ \\
\hline G9 & $\begin{array}{r}-2 \\
+j 3 \\
\end{array}$ & $\begin{array}{r}-3 \\
+\mathrm{j} 1 \\
\end{array}$ & $\begin{array}{r}-4 \\
+j 1 \\
\end{array}$ & +294 & $-\mathrm{j}$ & $\begin{array}{c}2 \\
-\mathrm{j} 2 \\
\end{array}$ & $\begin{array}{c}0 \\
-j 0 \\
-j 0\end{array}$ & $\begin{array}{r}-312 \\
+\mathrm{j} 34 \\
\end{array}$ & $\begin{array}{c}2 \\
-\mathrm{j} 2\end{array}$ & $\begin{array}{l}-310 \\
+\mathrm{j} 33\end{array}$ & $\begin{array}{c}4 \\
-j 1 \\
\end{array}$ & $\begin{array}{c}6 \\
-j 11 \\
\end{array}$ & $\begin{array}{c}6 \\
-j 1 \\
\end{array}$ & $\begin{array}{l}78 \\
-11\end{array}$ & $\begin{array}{r}-0 \\
+j 0 \\
\end{array}$ & $\begin{array}{r}-15 \\
+j 0 \\
\end{array}$ & $\begin{array}{r}-4 \\
+j 0 \\
\end{array}$ & $\begin{array}{r}-26 \\
-j 20 \\
\end{array}$ & $\begin{array}{r}-19 \\
+\mathrm{j} 1 \\
\end{array}$ & $\begin{array}{l}-45 \\
-\mathrm{j} 19 \\
\end{array}$ \\
\hline $\mathrm{G} 10$ & $\begin{array}{c}-2 \\
+j 3\end{array}$ & $\begin{array}{c}-3 \\
+j 1 \\
\end{array}$ & $\begin{array}{r}4 \\
+j 1\end{array}$ & $\begin{array}{c}2 \\
-\mathrm{j} 17\end{array}$ & $-j$ & $\begin{array}{c}2 \\
-\mathrm{j} 2\end{array}$ & $\begin{array}{c}0 \\
-\mathrm{j} 0\end{array}$ & $\begin{array}{r}-310 \\
+\mathrm{j} 34 \\
\end{array}$ & $\begin{array}{c}2 \\
-j 2\end{array}$ & $\begin{array}{r}-308 \\
+j 33\end{array}$ & $\begin{array}{c}4 \\
-\mathrm{j} 1\end{array}$ & $\begin{array}{c}6 \\
-j 1\end{array}$ & $\begin{array}{c}6 \\
-j 1\end{array}$ & $\begin{array}{c}13 \\
-\mathrm{j} 14\end{array}$ & $\begin{array}{r}-0 \\
+j 0 \\
\end{array}$ & $\begin{array}{r}-15 \\
+\mathrm{j} 0\end{array}$ & $\begin{array}{c}-4 \\
+j 0 \\
\end{array}$ & $\begin{array}{l}-26 \\
-j 20\end{array}$ & $\begin{array}{l}-19 \\
+\mathrm{j} 1\end{array}$ & $\begin{array}{l}-45 \\
-\mathrm{j} 19\end{array}$ \\
\hline G11 & $\begin{array}{c}0 \\
-\mathrm{j} 0\end{array}$ & $\begin{array}{c}0 \\
-\mathrm{j} 0\end{array}$ & $\begin{array}{c}0 \\
-\mathrm{j} 0\end{array}$ & $\begin{array}{c}0 \\
-\mathrm{j} 0\end{array}$ & $\overline{0}$ & $\begin{array}{c}0 \\
-j 0\end{array}$ & $\begin{array}{c}0 \\
+\mathrm{j} 0\end{array}$ & $\begin{array}{c}0 \\
-\mathrm{j} 0\end{array}$ & $\begin{array}{c}0 \\
-\mathrm{j} 0\end{array}$ & $\begin{array}{c}0 \\
-\mathrm{j} 0\end{array}$ & $\begin{array}{l}-1 \\
-j 0\end{array}$ & $\begin{array}{l}-2 \\
-\mathrm{j} 0\end{array}$ & $\begin{array}{l}-2 \\
-j 0\end{array}$ & $\begin{array}{l}-1 \\
-j 1\end{array}$ & $\begin{array}{r}-88 \\
-\mathrm{j} 41\end{array}$ & $\begin{array}{c}-3 \\
-\mathrm{j} 4\end{array}$ & $\begin{array}{c}3 \\
\text { j10 }\end{array}$ & $\begin{array}{l}-101 \\
-\mathrm{j} 45\end{array}$ & $\begin{array}{c}1 \\
+\mathrm{j} 7\end{array}$ & $\begin{array}{l}-100 \\
-j 38\end{array}$ \\
\hline $\begin{array}{l}\text { Col. } \\
\text { Sum }\end{array}$ & $\begin{array}{r}-23 \\
+\mathrm{j} 24\end{array}$ & $\begin{array}{l}-7 \\
-j 6\end{array}$ & $\begin{array}{c}-9 \\
-\mathrm{j} 10\end{array}$ & $\begin{array}{r}315 \\
+332\end{array}$ & 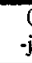 & $\begin{array}{c}1 \\
-j 1\end{array}$ & $\begin{array}{c}0 \\
+\mathrm{j} 0\end{array}$ & 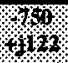 & 11 & 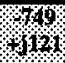 & $\begin{array}{l}-18 \\
-j 8\end{array}$ & $\begin{array}{l}-27 \\
-\mathrm{j} 10\end{array}$ & $\begin{array}{l}-28 \\
-\mathrm{j} 10\end{array}$ & 419 & $\begin{array}{l}-90 \\
-j 40\end{array}$ & $\begin{array}{l}-181 \\
+\mathrm{j} 70\end{array}$ & $\begin{array}{r}-46 \\
+\mathrm{j} 21\end{array}$ & 1149 & 127 & 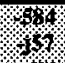 \\
\hline
\end{tabular}

example, the local-area mode involves generators 9 and 10 swinging against the rest; consequently in Table II the real parts of $\Delta \lambda_{i i}^{h}$, are -294 units for G9 and G10 compared to -26 for G1 to G4.

- For the inter-area mode, because of the larger number of machines participating, the speed participations are relatively low than for local modes (see Fig. 3). The left shifts associated with the real parts of $\Delta \lambda_{i i}^{h}$, for inter-area modes are thus smaller than those of the local mode, e.g. -78 units for G9 and G10 compared to -294 for the local mode. As a result of the effects of interactions and lower speed participation, the total left shift in the inter-area mode ( -357 units) is significantly less than that for the local-area mode $(-750)$ for the same increments in PSS gains.

- For a given mode the sum of the diagonal elements in Table II represents the total left-shift associated with the self-contributions of the PSS's only. For the local- and inter-area modes the sums are $-725+j 111$ and $-65-j 24$ units, respectively, compared to the actual total shifts due to PSS's only of $-750+j 122$ and $-337-j 130$ units. Interactions have thus enhanced slightly the damping of the local mode but have significantly degraded that of the inter-area mode. This degradation in damping of inter-area modes has been observed in practice in a range of studies on different power systems and in part can account for the relatively poorer damping of inter-area modes observed.

Note that from the columns of Table II the interactions between PSS's fitted to generators in the same station can be assessed. For both modes such interactions degrade somewhat the
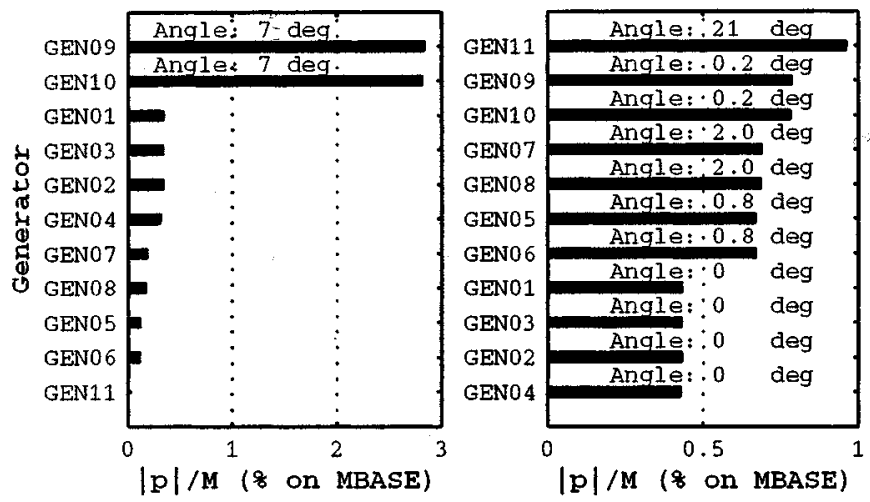

( 90$)-0.824+8.2125 J$

(102) $-0.294+3.7368 \mathrm{~J}$

$M$ is twice the inertia constant on machine rating

Fig. 3. Case A: Inertia-weighted (M) speed-participation factors $(p)$ for localand inter-area modes.

contribution to damping by the selected generator/PSS unit in this case. For example, due to the interaction from generator 10 the contribution to damping of generator 9 due to PSS 9 is degraded from -294 to -292 units and from -78 to -65 units for the local- and inter-area modes, respectively.

It is important to note through (5) that, as for PSS's, the damping introduced by FDS $j$ is determined by the ITC's $\Delta D_{i j}^{h}$ and the same factors $p_{i h} / M_{i}$ of the generators. For the local mode the ITC's - and hence the modes shifts-due to both FDS's are negligible. For the inter-area mode, however, the total left-shift due to the FDS's is significant, bang about $2 / 3$ rd of the total due to PSS's ( -227 and -357 units respectively); 


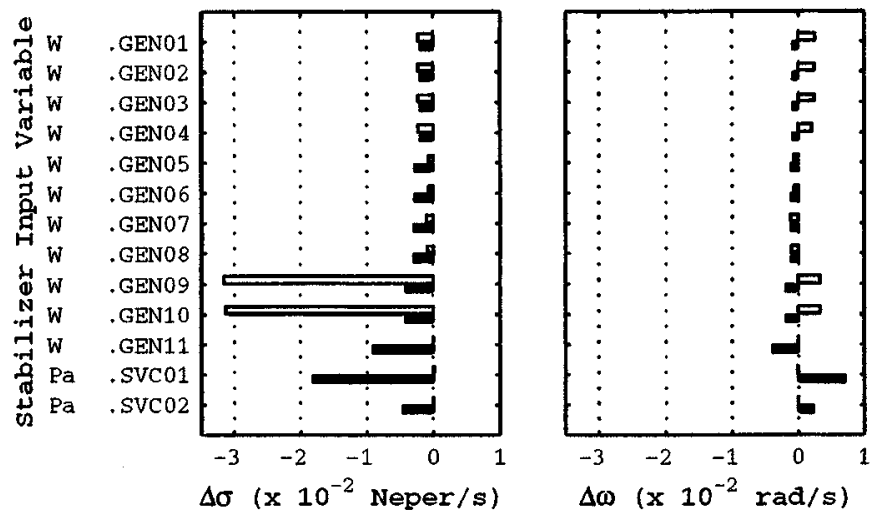

MODE $(90)-0.824+8.2125 \mathrm{~J}$ TotalShift $-0.075+0.0121 \mathrm{~J}$ MODE (102) $-0.294+3.7368 \mathrm{~J}$ TotalShift $-0.058-0.0057 \mathrm{~J}$

$\Delta \boldsymbol{\sigma}(\Delta \omega)=$ shift in real (imaginary) part of eigenvalue

Fig. 4. Case A: Stabilizer damping contribution diagram for local- and inter-area modes.

the FDS's therefore enhance the damping of the inter-area mode considerably.

\section{Stabilizer Damping Contribution Diagram}

As explained in Section IV above, the net contribution of stabilizer $j$ to the damping of mode $h$ is given by (9) or (15); this contribution is the column sum for stabilizer $j$ in Table II.

To assess the relative effectiveness of the stabilizers concerned the contributions to the mode shift of many PSS's and FDS's may need to be examined jointly and compared. This is meaningfully implemented in the form of a stabilizer damping contribution diagram shown in Fig. 4 . The diagram shows for a given mode the net contributions of selected stabilizers to the real parts $(\Delta \sigma)$ and imaginary parts $(\Delta \omega)$ of the mode shift for a simultaneous gain increment $\Delta k_{j}$ on each stabilizer. Each bar represents the component of the mode shift for a gain increment of $1 \mathrm{pu}$ on machine base for PSS's and 5\% of the maximum allowable setting for FDS's (defined in Section VII). From the diagram, it is possible to assess the effects of both positive, zero or negative gain increments on individual stabilizers. Accurate information on the contribution of each stabilizer to damping can be determined for gain increments typically in the range -5 to 5 pu for PSS's, and $\pm 10 \%$ of the maximum allowable gain setting for FDS's [6].

In order to demonstrate the significance of the stabilizer damping contribution diagram and its interpretation on a larger power system, which includes other types of FACTS devices, a further case study is examined.

\section{A. Case Study B: Application of the Stabilizer Damping Contribution Diagram}

The power system shown in Fig. 5 is a three-area, interconnected system having 28 generator groups and four FACTS devices fitted with FDS's. The power system is based on the South-East Australian system but is not a faithful representation of it. The FACTS devices consist of a HVDC link, a thyristor-controlled series capacitor (TCSC), and SVC's. Area 3 imports $420 \mathrm{MW}$ and $400 \mathrm{MW}$ over the DC and AC interconnections, respectively. All generators and FACTS devices

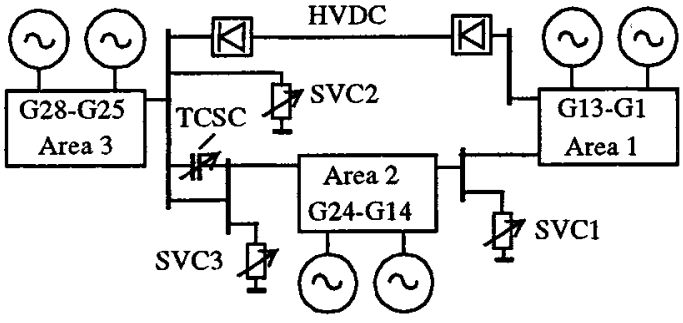

Fig. 5. Three-area power system.

TABLE III

LIGHTLY DAMPED MODES

\begin{tabular}{|cccc|}
\hline Mode & Type & Mode & $\begin{array}{c}\text { Damping } \\
\text { Ratio }\end{array}$ \\
\hline 237 & LA & $-0.60 \pm j 7.7$ & 0.078 \\
239 & LA & $-0.67 \pm j 7.5$ & 0.088 \\
254 & LA & $-0.27 \pm j 6.6$ & 0.041 \\
263 & IA & $-0.19 \pm j 4.7$ & 0.040 \\
269 & IA & $-0.15 \pm j 3.4$ & 0.043 \\
\hline
\end{tabular}

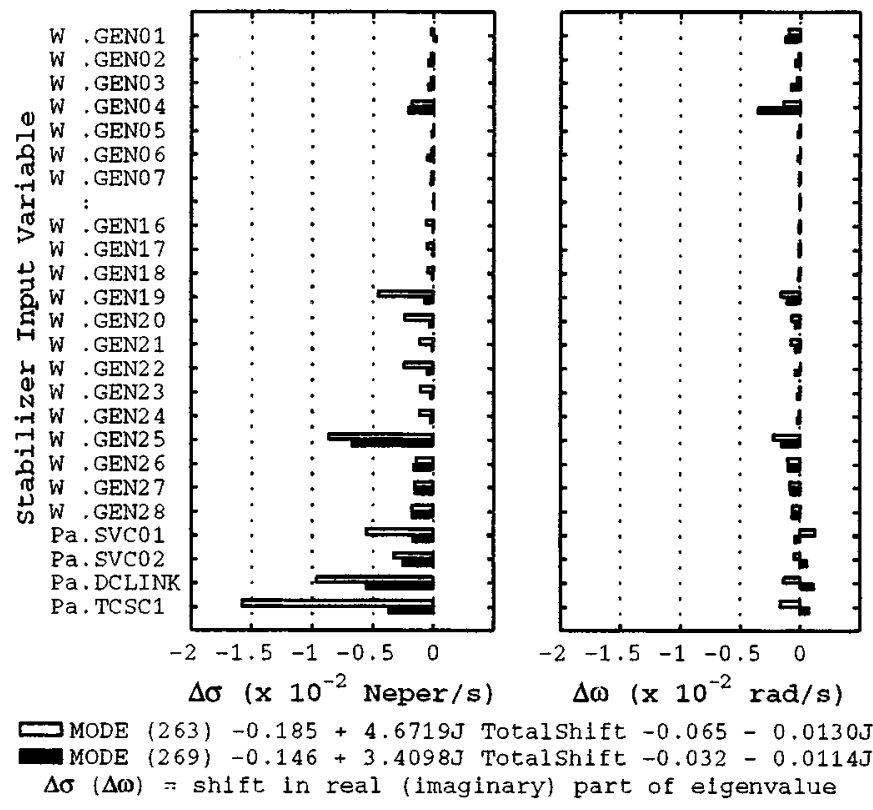

Fig. 6. Case B: Stabilizer damping contribution diagrams for inter-area modes.

are fitted with stabilizers using local stabilizing signals. The initial gain settings on stabilizers are: - PSSs: 5pu on machine MVA; FDSs: $0 \%$ of maximum allowable setting. The inter-area modes (IA) and some of the lightly-damped local-area modes (LA) are given in Table III. The stabilizer damping contribution diagrams for the lightly-damped inter- and local-area modes are given in Figs. 6 and 7 respectively. The contributions to damping from those stabilizers omitted from the diagrams are negligible. An examination of the real and imaginary parts of the damping contributions reveals that:

- FDS's fitted to TCSC, SVC1, SVC2 and the HVDC link contribute effectively to the damping of both the inter-area modes for the particular operating condition; 

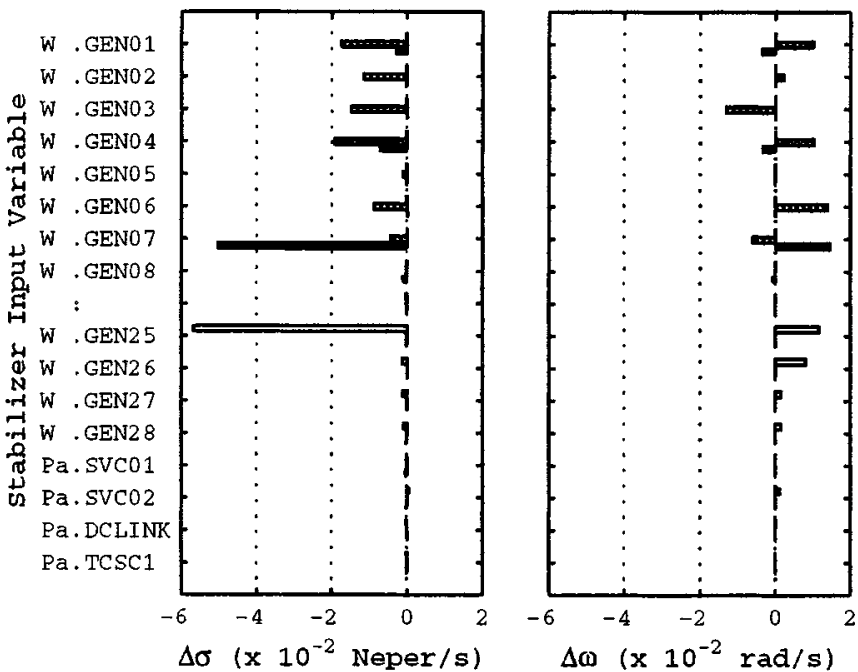

$\Xi$ MODE (237) $-0.597+7.6825 \mathrm{~J}$ Totalshift $-0.060+0.0244 \mathrm{~J}$ WODE (239) $-0.666+7.5408 \mathrm{~J}$ Totalshift $-0.078+0.0173 \mathrm{~J}$ $\longrightarrow$ MODE (254) $-0.268+6.5586 \mathrm{~J}$ Totalshift $-0.066+0.0060 \mathrm{~J}$ $\Delta \sigma(\Delta \omega)=$ shift in real (imaginary) part of elgenvalue

Fig. 7. Case B: Stabilizer damping contribution diagrams for local-area modes.

- of all the PSS's, surprisingly only PSS25 in area 3 is significantly effective in damping both the inter-area modes 263 and 269, however, increasing the gains of PSS's 19 to 28 in areas 2 and 3 could significantly improve the damping of inter-area mode 263;

- PSS7 and PSS25 control the damping of the lightly-damped local-area modes 254 and 237, respectively; PSS's 1 to 4 , as well as 6, are the most effective for enhancing the damping of local-area mode 239;

- the PSS and FDS design procedures have resulted predominantly in left shifts of the rotor modes - despite the effects of interactions discussed in Section IV.

Adjusting the gains of the above-mentioned stabilizers would thus achieve the most significant improvement in damping of the lightly-damped modes. A relatively large adjustment in the gains of other stabilizer (eg PSS23) would be required in order to make useful contributions to damping. Stabilizer damping contribution diagrams, and the information on the relative effectiveness of stabilizers, therefore provide a basis for the systematic coordination of PSS's and FDS's.

\section{DISCUSSION \& CONCLUSIONS}

\section{A. Interactions}

Analysis of interactions is based on PSS and FDS TF's being of the form $\left[k i \cdot G_{i}(s)\right]$. TF $G_{i}(s)$ is designed to effect a leftshift of the rotor modes, the extent of the left-shift being determined primarily by gain $k_{i}$. It is shown that, for an increment in PSS gain $\Delta k_{i}$ the self-induced torque coefficient on generator $i$ and the associated self-contribution to the shift in mode $h$ are $\Delta D_{i i}^{h} \approx \Delta k_{i}$ and $\left.\Delta \lambda_{i i}^{h}=-p_{i h} / M_{i}\right) \Delta D_{i i}^{h}$, respectively. This is consistent with PSS design techniques, however, due to interactions from other generators, $\Delta D_{i i}^{h}$ and $\Delta \lambda_{i i}^{h}$ may be enhanced or degraded. Hence,
- Machines with higher inertia-weighted participations, $p / M$, are the more effective contributors to damping.

- For local modes, which typically have only a few machines participating, the magnitudes of the factors $p / M$ for the dominant machines are significantly larger than those for the more numerous machines participating in the inter-area modes. Thus the self-contributions to damping $\Delta \lambda_{i i}^{h}$ by dominant machines are likely to be less for inter-area modes than for local modes.

- For inter-area modes, the effect of interactions is to degrade further the already lower self-damping contribution $\Delta \lambda_{i i}^{h}$ of generator $i$. As is shown in the case studies and observed in practice, the damping of inter-area modes is generally poorer than local. modes and is more difficult to improve using PSS's. The damping of local modes may be enhanced by interactions (as observed in [2]).

- The case studies show that jointly the damping of several inter-area modes can be enhanced significantly by FDS's fitted to FACTS devices placed at suitable locations; their effect on the damping of local-area modes in these cases is small, however, this will be system and operating condition dependent.

- For the inter-area modes the FDS's in Case Study A induce positive damping torques on the generators and thus contribute to damping by each generator. In this case, the interactions between the FDS's and the PSS's are positive, ie. an increment in FDS gain $\Delta k_{j}$ enhances the selfdamping resulting from an increment in PSS gain $\Delta k_{i}$ on generator $i$.

It can be shown that the term $-\sum_{i=1}^{n}\left(p_{i h} / M_{i}\right) \varphi_{i j}\left(\lambda_{h}\right)$ in (9) is the residue from the voltage reference to the speed output on machine $j$. However, information on interactions provided by (8) is not available through the analysis of residues.

\section{B. Relative Effectiveness of Stabilizers}

- The stabilizer damping contribution diagram is a simple, productive tool for displaying simultaneously the contributions to damping by some or all of the PSS's and FDS's. Hence those stabilizers which make the most significant contributions to the damping of rotor modes can be identified rapidly.

- Such diagrams provide the engineering insight and basis for the simultaneous coordination of PSS's with PSS's, and PSS's with FDS's [7]. These aspects have been found to be particularly valuable in practical applications.

- The disadvantage of the diagram is that it applies to small increments in stabilizer gains. However it has been found, for example, that mode shifts due to PSS gain increments of \pm 5 pu on machine base are accurate typically within $5 \%$.

\section{APPENDIX}

\section{A. Design of PSS's and FDS's in Multimachine Systems}

The stabilizer TF's are both of the form $\left[k_{i} . G_{i}(s)\right]$. Including wash-out and low-pass filters, $G_{i}(s)$ takes the form,

$$
K_{0}\left(s+\cdots+b_{m} s^{m}\right) /\left(1+\cdots+a_{n} s^{n}\right), \quad m \leq n,
$$


and is designed to achieve a left-shift in the relevant modes of rotor oscillation. The gain $k_{i}$, which is referred to as the 'gain' of the PSS or FDS, determines the extent of the left-shift.

1) Design of Multimachine PSS's [2]: The approach, which is used by a number of Australian utilities, is an extension of the single-machine case [1] to the multimachine problem. The aim of the design procedure is to introduce on the generator shaft a damping torque (a torque proportional to machine speed), this causes the modes of rotor oscillation to be shifted to the left in the $s$-plane. The ideal TF between speed and electrical torque perturbations over the range of complex frequencies of the rotor modes should be

$$
D_{e i}=\Delta P_{i i}(s) / \Delta \omega_{i}(s),
$$

where $D_{e i}$ is a damping torque coefficient and is a real number (pu on the machine base). The TF $G_{i}(s)$ compensates in magnitude as well as phase for the TF $H_{P V r_{-} i i}(s)$ of machine $i$, defined following (3) for the multimachine case. Assuming rotor speed is used as the input signal to the PSS, with output $V_{s i}$, the right-hand side of (17) can be written: $\left(\Delta P_{i i} / \Delta V_{s i}\right)\left(\Delta V_{s i} / \Delta \omega_{i}\right)=H_{P V r_{-} i i}(s)\left[k_{i} G_{i}(s)\right]=D_{e i}$, or $\left[k_{i} G_{i}(s]=D^{e i} / H_{P V r_{-} i i}(s)\right.$. Hence, ideally $k_{i}=D_{e i}$ and $G_{i}(s)=1 / H_{P V r_{-} i i}(s)$. The gain $k_{i}$ the PSS can thus also be considered to be a damping torque coefficient. The practical, proper TF for the $i$-th PSS is: $\left[k_{i} G_{i}(s)\right]=k_{i}\left(1 / P V R_{i}(s)\right) \cdot($ washout+low-pass filters), where $P V R_{i}(s)$ is the synthesized form of $H_{P V r_{-} i i}(s)$. As most rotor modes are relatively lightly damped, $s$ can be replaced by $j \omega$, and conventional frequency response methods can be employed in the design procedure. The aim of a design is to ensure that, over the range of frequencies of rotor oscillations, the magnitude response of (17) is flat with zero or slightly lagging phase shift. Because of the more-or-less invariant nature of the TF $H_{P V r_{-} i i}(s)$ over a wide range of operating conditions, fixed-parameter PSS's are robust [3], [8]. The tuning methodology summarized above is essentially the same as that described in [9] for tuning integral-of-accelerating-power PSS's.

2) Design of FDS's in Multimachine Systems [6]: A practical form of the FDS TF $H_{f d s_{-j} j}(s)$ is $\left[k_{j} G_{j}(s)\right]=k_{j}\{(1+$ $\left.\left.s \tau_{1}\right) /\left(1+s \tau_{2}\right)\right\}^{P}$ (washout + low-pass filters). For an increment $\Delta k_{j}$ in the gain of FDS $j$ the shift in the mode

$$
\Delta \lambda_{j}^{h} \approx r^{h}\left[G_{j}\left(\lambda_{h}\right) \Delta k_{j}\right] \quad \text { if }\left\|r^{h} \partial H_{f d s_{-} j}\left(\lambda_{h}\right) / \partial \lambda_{h}\right\| \ll 1,
$$

where $r^{h}$ is the residue from the reference input to FACTS controller $j$ to the input signal to the FDS. The mode shift $\Delta \lambda_{j}^{h}$ is directly to the left in the $s$-plane if $\arg \left[r^{h} G_{j}\left(\lambda_{h}\right)\right]= \pm 180^{\circ}$. The extent of the mode shift is proportional to $\Delta k_{j}$. The design procedure is to select $\tau_{1}, \tau_{2}, p$ in the FDS TF such that the appropriate phase compensation over the relevant rotor modes is derived. For a SVC, the maximum allowable value of gain, which is less than the limiting value given by (18), is that below which the terminal voltage response is not significantly affected by the stabilizer loop.

\section{REFERENCES}

[1] F.P. de Mello and C. Concordia, "Concepts of synchronous machine stability is affected by excitation control," IEEE Trans. PAS, vol. 88, pp. 316-329, 1969.

[2] M.J. Gibbard, "Coordinated design of multimachine power system stabilisers based on damping torque concepts," Proc. IEE, pt. C, vol. 135, pp. 276-284, July 1988.

[3] M.J. Gibbard, "Robust design of fixed-parameter stabilizers over a wide range of operating conditions," IEEE Trans. on Power Systems, vol. 6, no. 2, pp. 794-800, May 1991.

[4] M. Klein, G.J. Rogers, and P. Kundur, "A fundamental study of inter-area oscillations in power systems," IEEE Trans. on Power Systems, vol. 6, no. 3, pp. 914-921, August 1991.

[5] B.R. Korte, "Application of power system stabilisers for the South Australian interconnection," in Proc. of the International Power Conference, Singapore, March 1993, pp. 398-403.

[6] R. Pourbeik and M.J. Gibbard, "Damping and synchronizing torques induced on generators by FACTS stabilizers in multimachine power systems," IEEE Trans. on Power Systems, vol. 11, no. 4, pp. 1920-1925, Nov. 1996.

[7] P. Pourbeik and M.J. Gibbard, "Simultaneous coordination of power system stabilizers and FACTS device stabilizers in a multimachine power system for enhancing dynamic performance," IEEE Trans. on Power Systems, vol. 13, no. 2, pp. 473-479, May 1998.

[8] D.M. Lam and H. Yee, "A study of frequency responses of generator electrical torques for power system stabilizer design," IEEE Trans. on Power Systems, vol. 13, no. 3, pp. 1136-1142, Aug. 1998.

[9] A. Murdoch, S. Venkataraman, R. A. Lawson, and W. R. Pearson, "Integral of accelerating power type PSS. Part 1-Theory, design, and tuning methodology," in PBS Winter Meeting, Feb. 1997, Paper PB-473-BC-0-12-1997.

Michael J. Gibbard (S'67, M'69) received the B.Sc.(Eng.) degree from the University of the Witwatersrand, S.Africa, in 1957, the Certificate in Bus. Admin. from the London School of Economics in 1961, and a Ph.D. degree from Queen's University, Canada in 1968. In 1958-60 he worked for Associated Electrical Industries, UK. He joined the Snowy Mountains Hydro-Electric Authority, Australia, from 1961-65. In 1969-70 he worked for Imperial Chemical Industries, Australia. From 1970 he has been at The University of Adelaide.

Pouyan Pourbeik (M'93) received B.E.(Hons.) and Ph.D. degree from The University of Adelaide in 1993 and 1997, respectively. Since May 1997 he has been working for Power Systems Energy Consulting, GE Energy Services. His current interests are power system modeling and analysis, generator testing, and modeling of combined-cycle power plant.

David J. Vowles (M'96) received B.Sc. degree \& B.E.(Hons.) degree in Electrical \& Electronic Engineering from The University of Adelaide in 1983 and 1984, respectively. He was employed by the Hydro-Electric Commission of Tasmania in 1984-87 and by Portland Smelter Services, Victoria in 1987-89. Prom 1993, he has worked as a research engineer at The University of Adelaide. 